\title{
1875 Yılına Kadar Türk Edebiyatında Endülüs
}

\section{Abdulsattar Elhajhamed}

Öz: Bu makalede Endülüs'ün Tanzimat öncesi Türk edebiyatındaki yeri ele alınmıştır. Klasik dönemde Endülüs konusu divan şairlerinin dikkatini pek çekmemiştir. Bununla birlikte Endülüs'ten Kerb Gâzî Destanı'nda ve İspanya Sefaretnamesi'nde bahsedilir. Tanzimat döneminde Endülüs'e ilk önem veren yazar Ziya Paşa olmuştur. Ziya Paşa, mensur ve manzum yazılarında Endülüs'ü ele almıştır. Endülüs Tarihi adlı eserinde ayrıntılı bir şekilde Endülüs tarihini okurlarına sunmuştur. Bu eser sayesinde o zamana kadar pek fazla ilgi görmeyen Endülüs tarih ve medeniyetine yönelik bir ilgi oluşmuş ve Tanzimat dönemindeki aydınların Endülüs'le ilgilenmelerine vesile olmuştur.

Ziya Paşa, Harâbât adlı eserinde Endülüs şiiri ve şairlerine yer vermiştir. Engizisyon Tarihi adlı eserinde Engizisyon mahkemesinin Endülüslülere karşı yaptığı zulüm ve işkenceleri dile getirmiştir. Ziya Paşa, farklı eserlerinde Endülüs medeniyetini İslam Medeniyetinin güzel bir numunesi olarak göstermiş, Avrupa medeniyetinin ortaya çıkmasında Endülüs'ün oynadığı önemli role dikkat çekmiştir.

Anahtar Kelimeler: Endülüs, Kerb Gâzî Destanı, İspanya Sefaretnamesi, Ziya Paşa

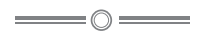

\section{Andalusia in Turkish Literature thru 1875}

Abstract: This article goes around the place of Andalusia before the Tanzimat Reform Era. In the classical period, Andalusia scarcely attracted the attention of divan poets. Yet, we see that the Ottomans talked about it in the epic Kerb Gâzî and in Ispanya Sefaretnamesi. Ziya Pasha was the first writer to attach importance to Andalusia in Tanzimat reform era by talking over Andalusia in both his prose and poetry. In his Endülüs Tarihi, he wrote about Andalusian history and civilization in detail, and thanks to this book, arose an interest in Andalusian history and civilization, which had not attracted much attention until then, and the intellectuals of Tanzimat Period became interested in Andalusia.

Ziya Pasha devoted a part of his book Harâbât to Andalusian poetry and poets, and in Engizisyon Tarihi, he spoke about the injustice and torture

"Okt. Dr, İstanbul Üniversitesi, Edebiyat Fakültesi, Arap Dili ve Edebiyatı Bölümü. abd.81@hotmail.com 
carried out by the Inquisition against Andalusians. He, in his various works, presented Andalusia as a great example of Islamic civilization, and drew attention to its role in the creation of Western civilization.

Keywords: Andalusia, Kerb Gâzî Destanı, İspanya Sefaretnamesi, Ziya Pasha.

\section{Giriș}

Endülüs (bugünkü İspanya), Akdeniz'in batı kısımlarında yer alan İberya Yarımadası'nın fethinden sonra Arapların bu topraklar için kullandığı coğrafi bir isimdir. 711 yılında fethedilen bu bölgede Müslümanlar yaklaşık sekiz yüz yıl kalmış, bu uzun zaman dilimi içerisinde büyük bir medeniyet inşa etmiş, fakat zamanla fethettikleri bu bölgeyi azar azar kaybetmişlerdir. 1492 yılında Endülüs'ün son hükümdarı olan Ebu Abdullah es-Sağîr'in Endülüs'ten Müslümanların elinde kalan Gırnata şehrini İspanyollara teslim etmesiyle Endülüs'teki Müslüman devleti sona ermiştir. Müslüman devleti yıkıldıktan sonra Endülüslüler, işkence ve zulme maruz kalmışlar, Müslümanların büyük bir kısmı Kuzey Afrika'ya göç etmek zorunda kalmışlardır.

Arapların yitik cennet dedikleri Endülüs, Müslümanlarca zamanla unutulmamıştır. Onun tarihini ve medeniyetini anlatan eserler yazılmıştır. Bu eserlerde Endülüslülerin her bakımdan muhteşem bir medeniyet kurdukları, bu medeniyetin dünyada ilmin gelişmesine katkıda bulunduğu, Avrupalıların bu medeniyetten birçok alanda faydalandıkları dile getirilir.

\section{Endülüs- Anadolu Kültürel İlişkileri}

Anadolu Türklerinin Endülüs ile kültürel bağlamdaki ilişkileri Selçuklular dönemine dayanır. Endülüslü mutasavvıf Muhyiddin İbnü’l-Arabî’nin (ö.638/1240) Anadolu'ya 1210 yılında gelişi, Endülüs-Anadolu kültürel ilişiklerinde önemli bir hadisedir. Endülüs'te doğan ve bir müddet orada hayat süren Muhyiddin íbnü’Arabî, ömrünün yaklaşık on yılını Anadolu'da geçirmiştir. Anadolu'da yaşadığı sürede Konya, Kayseri, Malatya, Sivas ve Aksaray gibi önemli şehirlere seyahatlerde bulunmuş, buralarda birçok talebe yetiştirmiştir.

Yetiştirdiği talebelerinden Sadreddin Konevî, onun bazı eserlerini şerh etmiş, dolayısıyla İbn Arabî’yi Anadolu'da tanıtmıştır (Tahralı, 1996:75). Böylece Endülüslü Muhyiddin İbnü’l-Arabî, Osmanlı irfanının teșekkülünde önemli bir yer tutmuştur. Niyâzî-i Mısrî (ö. 1105/1694), Nâbî (ö. 1124/1712), İsmâil Hakkı Bursevî (ö. 1137/1725), Abdullah Salâhaddin Uşşâkî (ö. 1197/1782) gibi Osmanlı şairleri, íbnü'l-Arabî ve eserleri hakkında methiye yazmışlardır (Şimşek, 2008: 389-425).

Fatih Sultan Mehmed'in döneminde Osmanlı âlimleri, Endülüs filozoflarından ỉbn Rüşd'ün eserleriyle ilgili birkaç şerh ve haşiye kaleme almışlardır. Osmanlı aydınları, Endülüslü âlimler kanalıyla tanıdıkları Endülüs'e değer vermişlerdir. Ayrıca, Osmanlı aydınları medrese eğitimi sırasında Endülüslü şairler ve onların eserlerinden genel Arap Edebiyatı aracılığıyla haberdar olmuşlardır (Ayvazoğlu, 1996: 80). 
Osmanlı Devleti'nin “zayıflama” sürecinde Osmanlı tarihçi ve aydınları, soyu Endülüslü bir aileye dayanan ve miladi 764-766 yılları arasında Gırnata'nın son İslâm devletinde önemli görevler yapan ỉbn Haldûn'a, özellikle de çöküşle ilgili teorilerini içeren Mukaddime'sine daha fazla ilgi duymuşlardır. İbn Haldun'un Mukaddime'sinden alıntı, tercüme, yorum yaparak onun tarih, toplum, siyaset gibi farklı alanlarda yaklaşımlarından yararlanmışlardır (Okumuş, 2006: 141-185).

Mukaddime'nin ilk beş bölümü Şeyhülislâm Pîrîzâde Mehmed Sahib Efendi (ö. 1749) tarafından1730 yılında tercüme edilmiştir. Mukaddime'nin son bölümü ise XIX. Yüzyıl ortasında Cevdet Paşa (1822-1895) tarafından Türkçeye çevrilmiştir.

\section{Tanzimat'tan Önce Türk Edebiyatında Endülüs}

Endülüs, Osmanlı dönemin halk edebiyatında da yer alır. Nitekim XVI. Yüzyıla ait olan Kerb Gâzî Destanı'nda Endülüs'ten söz edilir. Bu destanda olayların bir kısmı Endülüs'te geçer. Destanda Endülüs'ün üç tarafı denizle çevrili ve bir tarafında da nehir akan bir kale olarak algılanması dikkat çekicidir:

“Adına sehr-i Endülüs der idi

Şehrin garb zeryayazen gelirdi

Şehrin hem bir cânibi deryâ idi

Irmak karışır zeryaya gider idi

Sürüp şehr-i Endülüs'e geldiler

Râviler bunda rivâyet kıldılar

Çün ol şehrin üç yani deryâ idi

Bir tarafı kuru beriyye idi" ('̇yiyol, 2014:114)

Destanda Endülüs'ün bir ülke olarak algılanmasının yanı sıra Endülüs'ü fethedenin Târık b. Ziyâd değil, destanın kahramanı Kerb Gâzî olduğu ifade edilir. Destanda Kerb Gâzî, olağanüstü kahramanlıklar yaparak Mağrib ve Endülüs'ü fetheder. Mağrib’i fethettikten sonra Endülüs kalesine sığınan HâmŞâh’ı takip eder. 400 kişiyle Endülüs kalesini fethetmeye çalışır. Fakat savaş sırasında büyük yaralar alır. Destanın diğer kahramanı Muhammed Hanif, Hz. Muhammed'in gömleğini Kerb Gâzî’ye ulaştırır. Kerb Gâzî, mübarek gömleği giyince bütün yaraları iyileşir. Mübarek gömleği giydikten sonra da artık ona hiçbir ok etki etmez olur. Kerb Gâzî, savaşın sonunda Endülüs kalesini fetheder ve buranın hükümdarı olur.

I.Abdülhamid döneminde Osmanlı Devleti tarafından 1787 yılında İspanya'ya elçi olarak gönderilen Vasıf Efendi, ${ }^{1}$ İspanya'dan dönüşünde

\footnotetext{
${ }^{1}$ Ahmed Vasıf Efendi (ö. 1806), Bağdat'ta doğmuş, ilk tahsilini orada yapmıştır. Kitapdarlık, Hacelik, Serkatibi, Vak'anüvislik ve Orta Elçilik gibi görevlerde bulunmuştur. III. Selim zamanında Vak’anüvis ve devlet adamı olarak
} 
kaleme aldığı İspanya Sefaretnamesi adlı eserinde i̇spanya'daki İslâm dönemine ait eserlerle ilgili izlenimlerini ve Endülüs tarihine dair bilgilerini dile getirir.

Vasıf Efendi, eserinde İspanya tarihine dair bilgiler verirken Müslümanların ìspanya'ya geliş sebepleri üzerinde de durur: "Got kralı i̇spanyolların beylerinin bir hüsna kızını cebren almak diledi ol dahi i̇slam'a haber gönderüb istimdad eyledi ve siz gelüb bu memleketi alasız dedi.” (Ahmed Cevdet Paşa, 1309: 356)

Müslümanların Endülüs'ten çıkma sebepleri üzerinde duran Vasıf Efendi, İspanya'da kurulan i̇slam devletine nifak sokulmasının ve yöneticilerinin çekişmeye başlayıp birbirlerine karşı İspanyollardan yardım almalarının devletin zayıflamasına sebep olduğunu ifade eder:

“...yedi sekiz yüz hilalinde nice devletler zuhur edüb cümlesi İslam'dan olmak üzere hüküm eylediler. Ve Endülüs'den dahi nice memleket feth eyledikten sonra derunlarına intilâl girüb ümeray-ı İslam birbirlerine düștüler ve küffardan istinsâr ederek birbirine kahr ederek müzmahil olub dokuz yüz tarihine gelince bilcümle diyar-ı Endülüs yed küffara giriftar oldu..." (Ahmed Cevdet Paşa, 1309: 356)

Vasıf Efendi, İspanya'da İslam döneminden kalma eserlerden söz eder. İspanya'daki İslam medeniyetinin izlerini sefaretnamesinin değişik sayfalarına serpiştirir. İskoçya'daki kütüphanenin bir manastırın içinde yer aldığını belirten Vasıf Efendi, kütüphaneyi gezer ve orada mevcut i̇slam eserlerini gözden geçirir. Vasıf Efendi, Endülüs'ün Franklar tarafından istila edilmesi sırasında burada bulunan eserlerin toplatılarak manastırda iki ayrı yere konmuş olduklarını, fakat bunlardan birisinin yandığını ifade eder.

Vasıf Efendi, manastırın kütüphanesinde on tane eski hat ile yazılmış Kur'an-ı Kerim ile çok sayda fıkıh, kelam ve hadis kitapları gördüğünde çok müteessif olduğunu söyleyerek duymuş olduğu üzüntüleri dile getirir (Ahmed Cevdet Paşa, 1309: 355).

Eski Türk edebiyatında bu iki eser hariç Endülüs'le ilgi eserlere rastlayamadık. Osmanlı şairlerinin Endülüs'le pek ilgilenmemiş olması dikkat çekicidir. "Endülüs'ün yıkılış dönemi, Osmanlı irfanının teşekkül etmekte olduğu dönemdir. Hem bu bakımdan, hem de Osmanlı coğrafyasına denizyolu dışında bağlantısının bulunmamasından" dolayı Endülüs, yaygın bir şekilde Türk klasik edebiyatına girememiştir (Ayvazoğlu, 1996: 80).

\section{Tanzimat Dönemi ve Endülüs}

Türk edebiyatçıları, Tanzimat'tan sonra daha sık Endülüs'ten bahsetmeye başlamışlardır. Tanzimat'tan sonra Batıılıaşma hareketinin hızlanmasıyla şartlar

meşhur olmuştur. Bir sefaretle İspanya’ya gönderilmiştir. Ramazan 1201/1 Temmuz 1787 tarihinde yola çıkmış ve on ay sonra 5 Şaban 1202/11 Mayıs 1788'de İstanbul'a dönmüştür. (Vasıf Ahmed Efendi, 1978: XVIII-XLVII). 
değişmeye başlamış, sonuçta Batı kültürü Türk Edebiyatı'nın yararlandığı en önemli kaynaklarından biri haline gelmiştir. Bu kültürün fikir adamlarından biri konumundaki Ernest Renan gibi bazı isimler, İslâm'ın ilerlemeyi engelleyen bir din olduğunu iddia etmişken Türk aydınları, bu düşünceyi çürütmek için harekete geçmiş, tarihî bilgileri ortaya koyarak cevap vermeye çalışmışlardır. Böylece Batı'nın İslâm'a karşı olumsuz bakışına tarih ile cevap vermek, yeni Türk edebiyatının genel problematiklerinden birini teşkil etmiştir (Uğurcan, 2002: 15). Batı'daki İslam karşıtı propagandalara cevap olarak Tanzimat dönemi yazarları, dört elle sarıldıkları Endülüs medeniyetini örnek olarak göstermişlerdir (Enginün, 2006: 64).

Öte yandan bu dönemde Osmanlı Devleti’ndeki Hristiyanların bağımsızlık istemesi, Türkiye'nin İslâm dünyasıyla olan ilişkilerini güçlendirmesine sebep olmuş ve böylece "ittihad-i i̇slâm politik bir ideoloji haline” gelmiştir (Tarhan, 2002: 7).

Dağılma tehlikesi yaşayan Osmanlı Devleti'nin durumunu hisseden Türk aydınları, manevî bir kuvvet kaynağı olan Türk ve İslâm tarihine yönelip İslâm'ın parlak dönemlerinden bahsetmeye başlamışlardır. Böylece Türk edebiyatçılarının yaşadıkları ortam, Endülüs tarihi hakkında eserler yazılmasına zemin oluşturmuştur.

\section{Ziya Paşa'nın Eserlerinde Endülüs}

Türk edebiyatçılarının Endülüs'e ilgileri Ziya Paşa'nın 1859 yılında Fransızcadan çevirdiği Endülüs Tarihi ile daha da belirginleşmeye bașlamıştır. ${ }^{2}$ Louis Viarot'a mahsus bu eserin ${ }^{3}$ çevirisine Mabeyin Müşiri Edhem Paşa başlamış, fakat çevirinin daha güzel olması için Mabeyn-i Hümayun'un beşinci kâtibi Ziya Paşa'ya teklifte bulunmuştur (Enginün, 2000: 33).

Ziya Paşa, esas konuya başlamadan önce kitabın ilk sayfalarında Endülüs medeniyeti hakkında yeterince bilgiye sahip olunmamasını büyük bir eksiklik olarak gördüğünü dile getirir. Ziya Paşa, İspanya'da yedi asırdan fazla bir süre hüküm süren İslam devletinin tarihi, orada Müslümanların oluşturdukları medeniyet, ortaya koydukları eserler ve uyguladıkları adaletli idare sistemi hakkında şimdiye kadar hiçbir eser yazılmadığını söyler. Ziya Paşa'ya göre Endülüs'ün diğer İslâm şehirlerinden uzak olması, Endülüs'ü ele geçirdikten sonra Hristiyanlar tarafından yapılan tahribatın sonucunda oradaki medeniyet unsurlarının ortadan kaldırılması ve tahribattan kurtulan pek az Arapça kaynağın bulunması nedeniyle Osmanlı Devleti bu büyük medeniyetin enkazından istifade edememiştir ( Ziya Paşa, 1304:I, 5).

\footnotetext{
${ }^{2}$ Endülüs Tarihi adlı eserin Ziya Paşa tarafından çevrilip çevrilmediği tartışmalıdır. Ziya Paşa, kitabın mukaddimesinde kitabın Louis Viardot'un eserinin tercümesi olduğunu açık bir şekilde söylememiştir. Fakat eser büyük ölçüde Viardot'un eserine dayanır. Ancak Ziya Paşa, Viardot'un kitabının bazı bölümlerini çıkartmakla birlikte bazı ilaveler ve bir takım kısaltmalar yapmıștır. (Enginün, 2006: 64)

${ }^{3}$ Kitabın asıl adı “Essai sur l'histoiredes Arabes et des Moresd 'Espangne” Paris.1833 (Lewis, 2001: 131)
} 
Endülüs Tarihi'nde İslâm medeniyetiyle Batı medeniyeti kıyaslanarak İslâm ve Arap medeniyeti yüceltilir. İslâm medeniyetinin ilme ve marifete verdiği önemden, fethettiği yerlere götürdüğü değerler ve düzenden söz edilir. Batı medeniyetinin Endülüs vasıtasıyla İslam medeniyetinden birçok şey aldığı belirtilir (Erünsal, 2015: 421-422).

Ziya Paşa, eserinde sadece tarihî vakıaları nakletmekle yetinmez, şahısların portrelerini çizer, tasvirlerini yapar (Ziya Paşa, 1304:I, 29). Olayları anlatırken kendi düşüncelerini de dile getirir. Ziya Paşa, bazen bir kişi veya olayı anlatırken bu kişi veya olay ile ilgili düşüncelerini bazen "ihtâr", bazen de "şikâyet" başlıkları altında sunar. Ziya Paşa'nın şikâyetleri, daha çok Avrupalı tarihçilerin Müslümanlar hakkında yaptıkları haksız eleştirilere karşı bir tepki olarak görülür. Ziya Paşa'nın şikâyetlerinin, daha çok Avrupalı tarihçilerin Müslümanlar hakkında yaptıkları haksız eleştirilere karşı bir tepki olduğu görülür. Ziya Paşa, bir şikâyetinde Hristiyan tarihçilerin yazdıkları eserlerinde sürekli dinî taassuptan etkilendiklerini şöyle dile getirir.

"Şikâyet: İspanya Hristiyanları millet-i İslâmiyye hakkındaki buğz u 'adâvetlerini bir hadde vardırmışlardır ki, tahrîr etdikleri târih kitaplarının her harfi tahtında bûy-i ta'assub istişmâm olunup, meselâ kendilerinin lehine ve Müslümanlar 'aleyhine dâ'ir bir vâkı'a ağız rivâyeti olsa bile tafsîlatıyla zikr olunmuş ve bil'akis Müslümanlar lehine ve kendülerinin'aleyhine müte'allik bir maslahat velev delâ'il-i vâzıha ile müberhen ve müteayyin olsun ya hiç yazılmamış ve yâhûd yazılmış ise de ifâdesinde ta'birât-ı hasmâne isti'mâl edilmiş olmağla, nazar-ı insâf ile bakılsa hakîkaten bunlar gayret-i dîniyye uğruna fedây-ı insâniyyet ve dirîğ-i hakkâniyyet eylemiş oldukları âşikârdır." (Ziya Paşa, 1304: III, 34-35)

Ziya Paşa eserinde övgü ve yergilere de yer verir. Şöyle ki Allah, Hz. Peygamber ve Müslümanları yüceltirken Hristiyanları tenkit ederek "korkak" ve "mutaassıp" sıfatlarını kullanmaktan çekinmez (Ziya Paşa, 1304: I, 4-5, 12-13, 25 , 97, 131). I. Abdurrahmân'ın Kurtuba'da cami, mektep, hastane ve kütüphane inşa ettiğini anlattıktan sonra şu ifadeye yer verir:

“Ehl-i İslâm'ın dahi medeniyyet ve insâniyyette neye muktedir olduğunu ‘âleme bildirdi” (Ziya Paşa, 1304: I, 71)

Endülüs Tarihi isimli bu eserin büyük bir kısmı içerik olarak çeviriye dayanır. Fakat Ziya Paşa'nın tercüme yapmakla yetinmeyip eserin farklı yerlerine birçok ilâvelerde bulunduğu ve değerlendirmeler yaptığı anlaşılır.

Önce 1863 yılında iki cilt, 1887 yılında da dört cilt hâlinde İstanbul'da yayınlanan Endülüs Tarihi, Türk edebiyatçılarının dikkatini üzerine çekmiş, o zamana kadar pek fazla ilgi görmeyen Endülüs tarihine ve medeniyetine yönelik bir ilgi oluşturmuştur. Endülüs Tarihi vesilesiyle Tanzimat döneminde aralarında Muallim Naci, Abdülhak Hamid, Şemseddin Sâmî gibi aydınların Endülüs'le ilgilenmelerine sebep olmuştur. Nâmık Kemâl'in Midilli'deyken gönderdiği mektupta Renan Müdâfaa-nâmesi adlı eserini hazırlamak için faydalanmak üzere 
istediği eserlerden biri Ziya Paşa'nın çevirisini yapmış olduğu Endülüs Tarihi'dir (Namık Kemal, 2013: III, 299).

Ahmet Hamdi Tanpınar, “... Endülüs Tarihi tercümesi zamanında çok okunmuştur. Mütercimin (Halil Edhem Paşa'nın yardımı yahut iştiraki doğru ise, mütercimlerin) hakkiyle tarih bilmemesi, hatta kitabın ikinci derecede bir eser olmasl, Ebüzziya'dan Muallim Naci'ye kadar Hâmid de içlerinde olmak üzere, mevzuunu Endülüs Tarihi 'nden alan birçok eserin doğmasında bir payı bulunmasına mâni olmamıştır." diyerek bu eserin Tanzimat dönemindeki edebiyatçılar üzerinde bıraktığı etkiye vurgu yapar (Tanpınar, 2006: 300). Arap dünyasında Arap fikir ve siyaset adamı olan Emir Şekîb Arslân da (1869-1946) Endülüs'e dair eserlerinde Endülüs Tarihi'ne atıf yapar (Arslân, 1983: 11, 276).

Ziya Paşa'nın Endülüs tarihine dair ikinci eseri, Mabeyn kâtipliği sırasında 1277 (1860-1861) ${ }^{4}$ yılında Théophile Lavallée ${ }^{5}$ ile Adolphe Chéruel'den çevirdiği Engizisyon Tarihi'dir. Bu eserde Engizisyon mahkemesinin ne zaman ve nasıl ortaya çıktığını anlattıktan sonra bu mahkemelerde özellikle Yahudilere yapılan zulümler ve işkenceleri anlatır. Ziya Paşa, kitabın önsözünde eserin Fransız yazarların kitaplarından özetleme yoluyla Türkçeye aktardığını ifade eder (Ziya Paşa, 1299: 4).

Ziya Paşa, İspanyol yöneticilerini tenkit ederek "ahmak”, “cahil” ve "mutaassıp” gibi sıfatlar kullanmaktan çekinmez. İspanya Kraliçesi'ni ve Hristiyan din adamlarını ağır bir dille eleştirmiştir (Ziya Paşa, 1299: 18-19, 22).

Ziya Paşa, yıllar boyunca Türk, Arap ve Fars edebiyatlarından seçip topladığı şiirleri Harâbât (1874-1875) adlı eserinde yayınlamıştır. Ziya Paşa, bu geniş kapsamlı antolojide Endülüs şiiri ve şairlerine önemli bir yer verir. Ayrıca Harâbât eserinin mukaddimesinin “Ahvâl-i Şuarâ-yı Arab” bölümünde beğendiği Ebi elVelid İbn Zeydûn, ibn Beşîr, ibn Şâtir, ibn Merec, ỉbn Leyûn, ibn Hafâce, ibn Sukre, Lisanuddin İbnü'l-Hatîb gibi meşhur Endülüslü şairlerin isimlerini zikreder (Ziya Paşa, 1291:102).

Ziya Paşa, seçmelerinde de Endülüslü şairlerin şiirlerine önemli bir yer verir. Harâbât'ın birinci cildinde Endülüslü şairler tarafından kaleme alınmış olan sekiz kaside bulunmaktadır (Ziya Paşa, 1291: 258-271). Endülüs'ün son şairlerinden Ebu'l-Bekâ er-Rundî’nin Risâül-Endelüs (Endülüs Mersiyesi) ${ }^{6}$ adlı şiiri ve ibn 'Abdûn el-Fehrî’nin (ö 529/1134) Batalyevs (Badajoz) hâkimi ve Eftasilerin son

\footnotetext{
${ }^{4}$ Engizisyon Tarihi, her ne kadar 1277 (1860-1861) tarihinde kaleme alınmış olsa da kitap olarak basımı Ziya Paşa'nın ölümünden sonra 1299 (1981-1982) tarihinde Ebüzziya Tevfik'in küçük mukaddimesiyle neşredilmiștir.

${ }^{5}$ Théophile Sébastien Lavallée (1804-1866) Fransız tarihçidir. Histoire de l'Empire Ottoman Depuisles Temps Anciens Jusqu' á nosJours (Eski Zamanlardan Günümüze Osmanlı İmparatorluğu Tarihi) adlı eseri vardır.

${ }^{6}$ Ziya Paşa'nın seçmelerinde yer alan Endülüs Mersiyesi iki defa Türkçeye aktarılmıştır. İlk olarak 1913 yılında Şam Birinci Türk Sultanisi Müdir-i Sânisi olan şair Filibelizade Mehmet Nizameddin tarafından tercüme edilmiştir. Filibelizade, mersiyeyi manzum olarak Türkçeye tercüme ederken, Şam Sultânisi'nin Arapça dersi hocası merhum Abdülkadir el-Mübarek'ten faydalanmıştır. İkinci olarak da şair Sezai Karakoç çevirmiştir. Mersiye, M. Grangaret tarafından Fransızca'ya, (Paris, 1878) A. F. Grafvon Schack tarafından Almancaya, (Berlin, 1865) Juan Valera tarafından İspanyolca'ya, (Madrid, 1867-1871) ve A. R. Nykl tarafından da ingilizce'ye (Baltimore, 1946) çevrilmiştir (Konrapa, 1964: 165), (Karakoç, 1985:85-90); (Toprak, 1990:197).
} 
hükümdarı olan Mütevekkil'in ölümünden sonra kaleme aldığı mersiye dikkat çekicidir. Ebu'l-Bekâ er-Rundî’ın harabeye dönüşen ve İspanyolların eline geçen Endülüs'ün farklı şehirlerine yazdığı mersiye şöyle başlar:

“Hengam-ı tamamında gelir her şeye nokşân;

Ömründeki hoşluklara aldanmasın insan.

Her şey mütelavvil, bu fena sence de meşhud,

Bir lahza meserret göreni kahreder ezman.” (Konrapa, 1964: 165)

Kaside ve mesnevi dışında kalan çeşitli nazım türlerindeki şiirlerden oluşan Harâbât'ın ikinci cildi ise Endülüs edebiyatından seçilmiş yirmiden fazla şiir içerir. Ziya Paşa, bu bölümde Ebu'l-Bekâ er-Rundî, İbn Cübeyr, İbn Leyûn, Lisânuddin b. el-Hatîb gibi meșhur Endülüslü şairlerin şiirlerine yer vermiştir (Ziya Paşa, 1291: 384, 389, 391, 399-400, 402-404, 412, 424-425, 428,433, 436-437, 446, 455, 468, $471-472,477,479,484,486,495,500-501,505)$.

Ziya Paşa, buhranlı bir dönemde yaşayan Müslümanlara moral vermek amacıyla Endülüs tarihine başvurmuştur (Erünsal, 2015: 422). Tanzimat döneminde" i̇slâm imiş devlete pâbend-i terakki" (Ziya Paşa, 1992: 121) rivayeti yeni çıktığında "Din terakkiye manidir" diyenleri tenkit ederken Endülüs medeniyetini örnek olarak göstermiştir. Avrupa medeniyetinin ortaya çıkmasında Endülüs'ün önemli bir rol oynadığını ifade etmiştir:

"Ger Endülüs olmasa Ziyadar,

Kim Avrupa'yı ederdi bîdar" (Ziya Paşa, 1311: 13)

Ziya Paşa, eserlerinde Endülüs'teki İslâmiyet'in şanlı günlerini hatırlattığı gibi Batının mazisindeki cehaleti ve taassubunu göstermeye çalışmıştır.

\section{Sonuç}

Anadolu Türklerinin Endülüs ile kültürel bağlamdaki ilişkilerinin Selçuklular dönemine dayanmasına rağmen Endülüs, divan şairlerinin dikkatini çekmemiştir. Bununla birlikte Endülüs'ün bir destan ve bir sefaretnamede yer aldığını tespit etmiştik. Kerb Gâzî Destanı'nda Endülüs'e dair bilgiler, coğrafi ve tarihî bilgilere ters düşmektedir. İspanya Sefaretnamesi adlı sefaretname, Vasıf Efendi'nin İspanya'daki İslâm dönemine ait eserlerle ilgili izlenimlerini ve Endülüs tarihine dair bazı bilgilerini ihtiva etmektedir.

Endülüs, Tanzimat'tan sonra Batılılaşma hareketinin hızlanmasıyla Türk edebiyatında önem kazanmıştır. Ziya Paşa başta olmak üzere Türk edebiyatçıları, İslâm medeniyetini savunurken sık sık Endülüs'ten bahsetmeye başlamışlardır. Ernest Renan gibi bazı isimler, İslâm'ın ilerlemeyi engelleyen bir din olduğunu iddia ederken, Ziya Paşa bu düşünceyi çürütmek için harekete geçmiş, farklı eserlerinde Endülüs medeniyetini örnek olarak göstermiş, İslam'ın terakkiye mani olmadığını savunmuş, Avrupa medeniyetinin ortaya çıkmasında Endülüs'ün 
önemli bir rol oynadığını dile getirmiştir. Türk edebiyatçılarının Endülüs'e ilgileri, Ziya Paşa'nın kaleme aldığı, Endülüs Tarihi ile daha da belirginleşmeye başlamıştır. Harâbât adlı eserinde Endülüs şiirinden örnekleri okuyucuya sunmuş, şairlerini tanıtmıştır. Engizisyon Tarihi adlı eserinde Engizisyon mahkemesinin yaptığı zulüm ve işkenceleri anlatarak Batı medeniyetinin teşekkülündeki olumsuz yönlere dikkat çekmiştir. Tanzimat edebiyatçılarının özellikle Abdülhak Hamid'in Endülüs'e yönelmesinde Ziya Paşa'nın Endülüs Tarihi adlı eseri önemli bir rol oynamıştır.

\section{Kaynakça}

Ahmed Cevdet Paşa. (1309). Tarih-i Cevdet (Cilt. 4) (2.bs.). Dersaâdet: Matbaa-i Osmaniye.

Arslan, E. Ş. (1983). Hulâsatü Târihi'l-Endelüs, Beyrut, Lübnan.

Ayvazoğlu B. (1996). Edebiyatımızda Endülüs, Endülüs'ten İspanya'ya içinde (ss. 79-85). Ankara: TDV.

Enginün, İ. (2000). Edebiyatımızda Endülüs, Araştırmalar ve Belgeler içinde (ss.3241). İstanbul: Dergâh Yayınları.

Enginün, i. (2006). Yeni Türk Edebiyatı Tanzimat'tan Cumhuriyet'e (1839-1923) (2.bs.). İstanbul: Dergâh Yayınları.

Erünsal,İ. (2015). Türk Edebiyatında Endülüs'e İlginin Uyanmasında Ziya Paşa'nın Endülüs Tarihi adlı Tercümesinin Rolü ve Bu Tercümenin Yapılıș Nedenleri, Mehmet Öz, Fatih Yeşil (Ed.). Ötekilerin Peşinde Ahmet Yaşar Ocak'a

Armağan içinde (ss. 417-423). İstanbul: Timaş Yayınları.

İyiyol, F. (2014). Kerb Gazi Destanı: Manzum (inceleme-metin). İstanbul: Sütun Yayınları.

Karakoç, S.(1985). İslam'ın Şiir Anıtlarından (5.bs.). İstanbul: Diriliş Yayınları, Konrapa, M. Z. (1964). Endülüs Mersiyesi Nizami Tercümesi ve Endülüs Tarihine Kısa Bir Bakış, İstanbul Yüksek İslam Enstitüsü Dergisi, 2, 165-187.

Lewis, B.(2001). İslam in History: Ideas, People, and Events in the Middle East, (New Edition, revised and expanded) (2.bs.). Open Court Chicago and La Salle: Illinois.

Namık Kemal. (2013). Namık Kemal'in Husûsî Mektupları: VI. Midilli Mektupları-II, (Cilt. 3) (2. bs.). Fevziye Abdullah Tansel (haz), Ankara: Türk Tarih Kurumu.

Okumuş E. (2006). İbn Haldûn'un Osmanlı Düşüncesine Etkisi, İslâm Araştırmaları Dergisi, 15, 141-185.

Okuyucu C. (1994). Manzum Halk Hikâyelerinin Yeni Bir Örneği “Kerbnâme”, Erciyes Üniversitesi Sosyal Bilimler Enstitüsü Dergisi, 5, 175-202.

Parlak, N. (2005). Ziya Paşa'nın Endülüs Tarihi ve Günümüz Türkçesiyle Neşrinde Yapılmış Okuma Yanlışlıkları, İslâmiyat, 8, 111-122.

Şimşek, S. (2008). Türk Edebiyatında i̇bnü'l-Arabî Methiyeleri Üzerine Bir Inceleme, Tasavvuf, İlmî ve Akademik Araştırma Dergisi (İbnü’l-Arabî Özel Sayısı-1), 21, 389-425.

Tahralı, M. (1996). Muhyiddin İbn Arabi ve Türkiye'ye Tesirleri, Endülüs'ten İspanya'ya içinde (ss. 69-78) Ankara: TDV. 
Tanpınar, A. H. (2007). XIX. Asır Türk Edebiyatı Tarihi (2.bs). Abdullah Uçman (Ed), İstanbul: YKY.

Tarhan A. H. (2002). Abdülhak Hamid Tarhan Tiyatroları 5, Tarık yahut Endülüs'ün fethi, ibn Musa yahut Zatü'l-Cemal, Tezer yahut Melik Abdurrahmanü's-Salis, Nazife, Abdullahü's-Sagir. İnci Enginün (Ed), İstanbul: Dergâh Yayınları.

Toprak, M. F. (1990). Endülüs Şiirinde Mersiye, Yayımlanmamış Doktora Tezi, Ankara: Ankara Üniversitesi, Sosyal Bilimler Enstitüsü.

Uğurcan, S. (2002). Abdülhak Hamid Tarhan'ın Eserlerinde Tarih, İzmir, Akademi Kitabevi.

Uğurcan, S. (2004). Türk Edebiyatında Endülüs İmajı: Fetih-Yükselme-Bozgun, İslâmiyât, 3, 89-104.

Vasıf Ahmed Efendi, (1978). Mehasinü'l-Âsar ve Hakaikü'l-Ahbar, Mücteba İlgürel (Ed.). İstanbul: İstanbul Üniversitesi Edebiyat Fakültesi.

Ziya Paşa, (1291). Harâbât, İstanbul: Matbaa-i Âmire.

Ziya Paşa, (1299). Engizisyon Tarihi, Kostantiniyye (İstanbul): Matbaa-i Ebüzziya.

Ziya Paşa, (1304). Endülüs Tarihi (Cilt. 1-3). (2.bs.). İstanbul: Karabet ve Kasbar Matbaas1.

Ziya Paşa, (1311). Mukaddime-i Harâbât (2.bs.). Kostantiniyye (İstanbul): Kitabhane-i Ebüzziya.

Ziya Paşa, (1992). Terci-i Bend ve Terkib-i Bend. Hüseyin Yorulmaz (Ed.). İstanbul: Çıdam Yayınları. 